\title{
Self-Curing Concrete:- with Poly-Ethylene Glycol
}

\author{
Vedant P. Chavan \\ 174140019 \\ Student, DCE VI, VJTI- Matunga-19 \\ Students of Civil \& Environmental Engineering Department \\ Veermata Jijabai Technological Institute, Matunga, Mumbai 400019.
}

\begin{abstract}
Today concrete is the most widely used construction material due to its high strength and durability. This concrete needs a congenial atmosphere for the development of strength, which is provided by curing for a minimum of 14 days as prescribed by IS Code. Any negligence in curing hampers the strength development directly. Today, the major concern for the entire world is the availability of water for future needs and coming generations.

Today in the construction industry the most improperly used material is water. The water demand is increasing day by day and the sources are depleting. To counter this water demand we have made a study on 'Self- Curing Concrete' which can drastically save the water used on the construction site. This study involves the use of shrinkage reducing admixture- PolyEthylene Glycol (PEG) which helps in self-curing of the concrete.
\end{abstract}

Keywords:- Curing, Self- Curing, Admixture, Poly-Ethylene Glycol, Strength of Concrete, Internal Curing, Self-Desiccation

\section{INTRODUCTION:}

Curing is the process used for promoting the hydration of the cement and consists of control of temperature and moisture movement from and into the concrete. Curing allows continuous hydration of cement and consequently continuous gain in the strength, once curing stops strength gain of the concrete also stops. Proper moisture conditions are critical because the hydration of the cement virtually ceases when the relative humidity within the capillaries drops below $80 \%$. Proper curing of concrete structures is important to meet performance and durability requirements. In conventional curing, this is achieved by external curing, where water is applied after mixing, placing and finishing. When concrete is exposed to the environment evaporation of water takes place and loss of moisture will reduce the initial water-cement ratio which will result in the incomplete hydration of the cement and hence lowering the quality and strength of the concrete. Evaporation in the initial stage leads to plastic shrinkage cracking and at the final stage of setting it leads to drying shrinkage cracking. Also curing decreases the temperature of concrete, which is necessary. At elevated temperature ordinary concrete loses its strength due to the formation of the cracks between two thermally incompatible ingredients, cement paste and aggregates.

Hence for proper development of strength and to avoid the development of major cracks at the initial stage, curing is the utmost important part after placing and finishing.

In the practical scenario, today curing is done by sprinkling water externally on the concrete (External Curing). However, proper curing is not achieved by this due to the non-availability of water and various other practical difficulties. In ordinary cases, every 1 cu.m. of concrete requires 3 cu.m. of water, out of which most of it is required for curing. Now this water used for external curing is left off causing run-off and evaporation and practically the entire water is wasted. As we know water is a valuable resource and is depleting at a very high rate. As we saw that a very high amount of water is utilized on the construction sites, out of which most is wasted, there is an urgent need to minimize this wastage and start saving water.

This can be achieved by SELF-CURING CONCRETE or INTERNAL CURING.

\section{LITERATURE REVIEW:}

Curing is the process of maintaining the temperature and humidity of concrete at the desired level, to achieve a constant rate of hydration helping concrete to gain strength. Curing can be done by various methods as listed below:

1) Water Curing
a) Ponding
b) Sprinkling
c) Wet Covering

2) Membrane Curing

3) Steam Curing
a) At normal pressure

b) At high pressure

4) Self/Internal Curing
a) Super- Absorbent Polymer (SAP)
b) Light Weight Aggregates (LWA)
c) Shrinkage Reducing Admixture

The study in this paper deals with the method of Self-Curing, by Shrinkage Reducing Admixture called Poly- Ethylene Glycol (PEG) in different dosage and finding the optimum dose of PEG required.

\section{SELF-CURING:}

The American Code ACI-308 defines self-curing as 'the process by which the hydration of cement occurs because of the availability of additional internal water that is not a part of mixing water.'

Conventionally curing is the creation of water not causing loss of water from the surface i.e. it takes place from outside to inside. In internal curing, it is a contrast. The curing is from INSIDE to OUTSIDE, utilizing the water-retaining materials inside, called water reservoirs.

This term Internal Curing is also referred to as Self- Curing.

\section{NEED OF SELF-CURING:}

The main purposes of developing self- curing are as described below:

1) The rapid depletion of water. Though water is regarded as the main enemy of concrete, it is only 
for hardened concrete. The fresh concrete requires optimum water content or proper mixing and to obtain and develop strength.

In the initial stages, while curing a lot of water is wasted, and various countries and state are facing water crises. Therefore, various measures are expected by the concrete industry to reduce the waste of water caused due to curing.

2) Disadvantages or Inefficiency of Conventional Curing.

a) It is inefficient for vertical members like piers, columns etc.

b) It is useless in water-scarce places where curing is neglected due to unavailability.

c) Improper curing due to labour causes crack development in the structure

d) In various cases, labour cannot manually cure the structure and the structure remains uncured causing no-development of strength.

Therefore Self- Curing is an important advanced and upcoming topic in the field and also forms the necessity of the hour.

\section{METHODS OF SELF-CURING:}

Currently, there are two major methods of internal curing.

1. The first method uses saturated porous lightweight aggregates to supply an internal source of water which can replace the water consumed by chemical shrinkage during cement hydration. Lightweight aggregate batched at a high degree of absorbed water may be substituted for normal-weight aggregates to provide "internal curing" in concrete containing a high volume of cementitious materials. High- cementitious concretes are vulnerable to self-desiccation and early-age cracking, and benefit significantly from the slowly released internal moisture.

2. The second method uses poly-ethylene glycol (PEG) which reduces the evaporation of water from the surface of concrete and also helps in water retention. The polymers added in the mix mainly forms hydrogen bonds with water molecules and reduce the chemical potential of the molecules which in turn reduces the vapour pressure thus reducing the rate of evaporation from the surface.

3. The third method uses super absorbent polymer (SAP) which absorbs water and converts it into a gel, then releases it slowly with time. This property was very useful when it comes to watering overtime as well as for concrete when we need a continuous water supply for curing. But the problem is an excess amount of SAP will leave the concrete with a large number of voids which in turn reduces the concrete strength and durability. A small amount of SAP on the other hand will have a negligible effect on the concrete performance. The amount of water added to the fresh concrete is one of the most important key factors that affect the concrete properties, including durability and strength. The water is an essential ingredient needed for the hydration process in the fresh concrete and the curing process in the hardened concrete at its early stages.

\section{PRINCIPLE OF SELF-CURING:}

Proper curing of concrete structures is important to meet performance and durability requirements. In conventional curing, this is achieved by external curing applied after mixing, placing and finishing. Self-curing or internal curing is a technique in which additional moisture is provided in concrete which is not a part of mixing, for more effective hydration of cement and to reduce self-desiccation.

\section{MECHANISM OF SELF-CURING:}

Continuous evaporation of moisture takes place from an exposed surface due to the difference in chemical potentials (Free energy) between the vapour and liquid phases. The polymers added in the mix mainly form hydrogen bonds with water molecules and reduce the chemical potential of the molecules which in turn reduces the vapour pressure, thus reducing the rate of evaporation from the surface.

\section{EXPERIMENTAL PROCEDURE OF SELF- CURING CONCRETE:}

For defining the basic characteristics of self- curing concrete, an experimental investigation was conducted to study the compressive strength and optimum dosage of PolyEthylene Glycol 400 (PEG- 400). The materials, mixture proportions, measurements and test method used in this study are described in this chapter.

\section{Mix design -}

M20 standard mix

Ratio: Cement: Sand: Aggregate- 1:1.5:3

Dose of Poly Ethylene Glycol (PEG-400): - 0.5\%, 1\% and $1.5 \%$ of cement by weight.

\begin{tabular}{|c|c|c|c|}
\hline Cube Set & 1 & 2 & 3 \\
\hline Cement $(\mathrm{kg})$ & 3.34 & 3.34 & 3.34 \\
\hline Sand $(\mathrm{kg})$ & 5 & 5 & 5 \\
\hline Aggregate $(\mathrm{kg})$ & 10 & 10 & 10 \\
\hline Water $(\mathrm{Lit})$ & 1.335 & 1.335 & 1.335 \\
\hline PEG- $400(\mathrm{~mL})$ & 17 & 34 & 51 \\
\hline
\end{tabular}

\section{Compression Strength Test:}

Age of sample $=7$ Days and 28 days

Size of cube $=15 \mathrm{~cm} \times 15 \mathrm{~cm} \times 15 \mathrm{~cm}$

Area of cube $=225 \mathrm{~cm} 2$

\begin{tabular}{|l|l|l|}
\hline PEG-400 (Dosage) & 7 days & 28 days \\
\hline $0 \%$ & $18.23 \mathrm{MPa}$ & $23.9 \mathrm{MPa}$ \\
\hline $0.5 \%$ & $22.44 \mathrm{MPa}$ & $30.57 \mathrm{MPa}$ \\
\hline $1 \%$ & $21.64 \mathrm{MPa}$ & $28.28 \mathrm{MPa}$ \\
\hline $1.5 \%$ & $19.33 \mathrm{MPa}$ & $28.2 \mathrm{MPa}$ \\
\hline
\end{tabular}




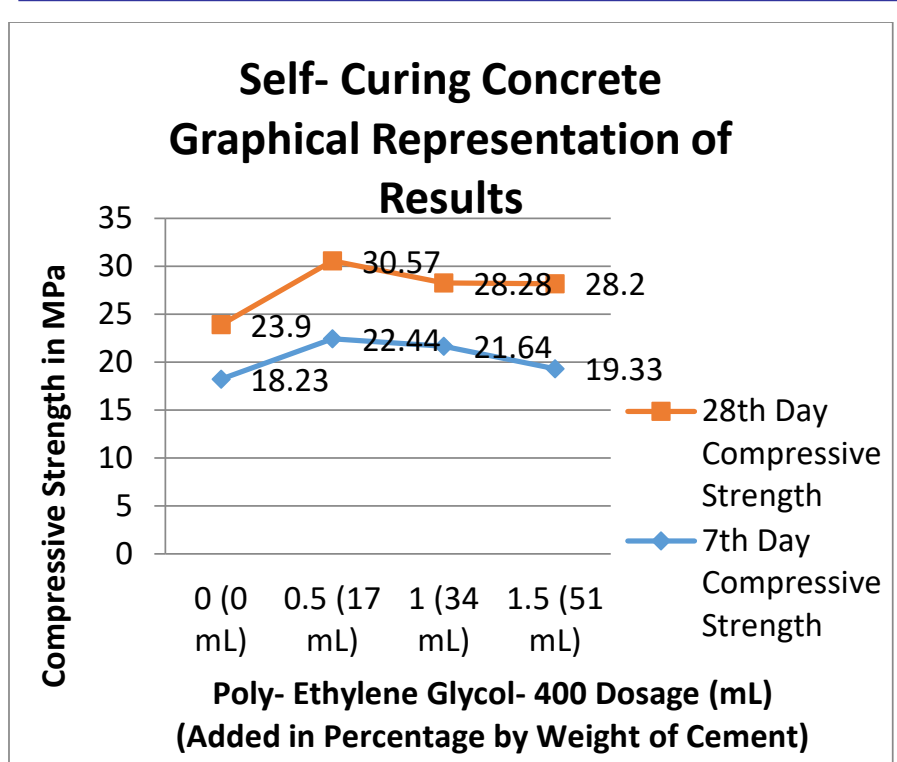

From the result, we can say that by $0.5 \%$ addition of PEG the increase in the compressive strength is $27.9 \%$ i.e. from 23.9 $\mathrm{MPa}$ to $30.57 \mathrm{MPa}$. But for $1 \%$ and $1.5 \%$ of PEG- 400 , there is only an increase of $18.32 \%$ in strength.

\section{MERITS OF SELF-CURING CONCRETE: -}

\section{Reduced coefficient of thermal expansion: -}

Studies showed that superabsorbent polymers (SAP) practically eliminate the increase in coefficient of thermal expansion throughout the initial days of hardening. They related the reduction of CTE to the high internal relative humidity of the investigated sample.

2. Improved interfacial transition zone: -

The interfacial transition zone (ITZ) between mineral aggregates is largely recognized as the weaker region within a concrete matrix. At the inception of hydration, the region nearest to the aggregate has average, fewer cement strains and is normally filled with water and pores. They also pointed out that concrete usually experiences stress concentration at the interfacial transition zone owing to different elastic ratios between aggregate and bulk cement paste resulting in micro cracks and macro cracks in concrete on load application.

\section{Reduced autogenous shrinkage and cracking: -}

Experimentally it is found that the addition of watersaturated LWA with a ground granulated blast furnace slag was valid for reduced autogenous shrinkage and cracking.

\section{Increased strength and durability: -}

Compressive strength of concrete is usually related to the curing age at a specified temperature and relative humidity. One of the key factors that promote high compressive strength in HPC is the compact nature of raw materials, which are attainable by low $\mathrm{w} / \mathrm{c}$ ratio and the equally filled small grains.

DEMERITS OF SELF-CURING CONCRETE: -

1) The material cost of SCC: -
This concrete is uneconomical because the cost per $\mathrm{m}^{3}$ for M15 grade is Rs. 3700 /- over Rs. 4560 /- of ordinary concrete.

\section{2) Availability of self-curing agents: -}

The availability of self-curing agents such as Light Weight Aggregate (LWA), poly-ethylene glycol (PEG) and super absorbent polymer (SAP) may be location specific and may have limited accessibility and availability.

\section{3) Limited development: -}

As compared to conventional curing more researches re to be done to harness the potential of self-curing. There are researches underway to improve its efficiency.

Rate Analysis:

SCC (1\%PEG)

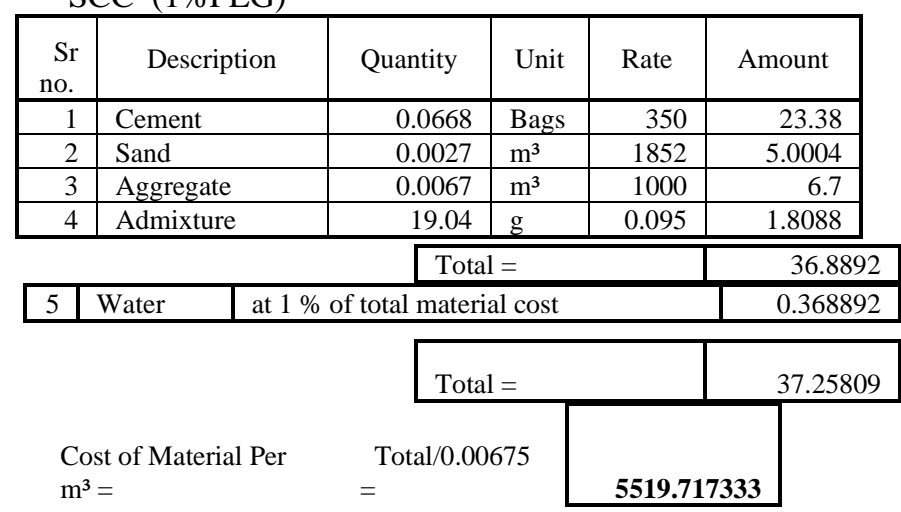

\section{CONCLUSION:}

From this study and experimental analysis, the following points can be concluded:

1) The development in the field of self- curing concrete, can answer various problems related to IMPROPER and INADEQUATE Curing in the construction field.

2) The amount of water being used, rather 'Wasted' can be efficiently saved and a minimal amount of water usage can be achieved on the construction sites.

3) The results of various other authors have shown that the strength of self- curing concrete is at par with ordinary concrete. The results from our experimental analysis will be soon updated in the paper with optimum dosage.

4) The concrete can prove economical over ordinary concrete as it is helping to save water.

\section{REFERENCES:}

[1] Basil M. Joseph, 'Studies On Properties of Self-Curing Concrete Using Poly-Ethylene Glycol (IOSR-JMCE)', 2016.

[2] Ryan Henkensiefken, Tomy Nantung, Jason Weiss, 'Reducing Restrained Shrinkage Cracking in Concrete: Examining the Behaviour of Self-Curing Concrete Made using Different Volumes of Saturated Lightweight Aggregate', 2008.

[3] Muddassir Bora, Mausam Vohra, Mohammed Sakil Patel, Dhruy Vyas; 'Self-Curing Concrete- Literature Review, ISSN:2321 9939'; Vol. 1 Issue 5, 2017 IJEDR.

[4] M. V. Jagannadha Kumar, M. Srikanth, Dr K. Jagannadha Rao; 'Strength Characteristics of Self Curing Concrete, ISSN: 23191163'; Vol. 1, Issue 1, September- 2001.

[5] V. Karthikeyan, S. Sasikumar, K. Sabarai, S. Seyatharasan; 'SelfCuring Concrete by using Super Absorbent Polymer (IJERT)'; Vol. 6, Issue 7, Special Issue 2018. 